Article

\title{
Rheological Tunability of Perovskite Precursor Solutions: From Spin Coating to Inkjet Printing Process
}

\author{
Antonella Giuri 1,2, Ehab Saleh ${ }^{3,4}$, Andrea Listorti ${ }^{2,5}$, Silvia Colella ${ }^{2,5}$, Aurora Rizzo ${ }^{2}$,
} Christopher Tuck ${ }^{3}$ (D) and Carola Esposito Corcione $1,2, * \mathbb{D}$

1 Dipartimento di Ingegneria dell'Innovazione, Università del Salento, via per Monteroni, km 1, 73100 Lecce, Italy; antonella.giuri@unisalento.it

2 Istituto di Nanotecnologia CNR-Nanotec, Polo di Nanotecnologia, c/o Campus Ecotekne, via Monteroni, 73100 Lecce, Italy; andrea.listorti@unisalento.it (A.L.); silvia.colella@unisalento.it (S.C.); aurora.rizzo@unisalento.it (A.R.)

3 Centre for Additive Manufacturing, Faculty of Engineering, University of Nottingham, Nottingham NG8 1BB, UK; E.Saleh@leeds.ac.uk (E.S.); Christopher.Tuck@nottingham.ac.uk (C.T.)

4 Future Manufacturing Processes Research Group, School of Mechanical Engineering, University of Leeds, Leeds LS2 9JT, UK

5 Dipartimento di Matematica e Fisica “E. De Giorgi”, Università del Salento, Via Arnesano snc, 73100 Lecce, Italy

* Correspondence: carola.corcione@unisalento.it

Received: 14 March 2019; Accepted: 4 April 2019; Published: 9 April 2019

\begin{abstract}
The high efficiencies ( $>22 \%$ ) reached by perovskite-based optoelectronic devices in a very short period, demonstrates the great potential and tunability of this material. The current challenge lies in translating such efficiencies to commercially feasible forms produced through industrial fabrication methods. Herein, a novel first step towards the processability of starch-perovskite inks, developed in our previous work, is investigated, by using inkjet printing technology. The tunability of the viscosity of the starch-perovskite-based inks allows the selection of suitable concentrations to be used as printable inks. After exploration of several printing parameters, thick and opaque starch-perovskite nanocomposite films were obtained, showing interesting morphological and optical properties. The results obtained in this work underline the potential and versatility of our approach, opening the possibility to explore and optimize, in the future, further large-scale deposition methods towards fully printed and stable perovskite devices.
\end{abstract}

Keywords: starch-perovskite inks; rheological tunability; inkjet printing

\section{Introduction}

Inkjet printing, traditionally used in the graphics and publishing industries, has proven to be an effective digital manufacturing technique for printed solar cells [1]. In this direction, the emergence of organic-inorganic hybrid perovskite solar cells has represented a breakthrough technology, combining solution-based deposition techniques with greater efficiencies than organic solar cells [1].

However, one of the most important challenges now for perovskite-based materials is improving stability and reproducibility during fabrication, particularly by translating the high performance obtained at laboratory scale to industrial fabrication methods [2-4].

Among the different potential techniques for depositing perovskite-based materials and other functional layers of a solar energy device, inkjet printing is one of the most frequently used on a laboratory scale due to its versatility and selectivity in the fabrication of functional layers from solutions 
or suspension inks [5]. The use of this deposition technique has many advantages, such as the low-cost process, the reduced waste of the ink during deposition, the easy deposition of fine patterns at high resolution on various substrates, and above all, the scalability, enabling rapid translation of learning from small-scale, laboratory-based research into large-scale industrial roll-to-roll manufacturing $[1,5,6]$.

The first application of inkjet printing of perovskite was reported in 2014 by Yang and co-workers [7] for the fabrication of metal-electrode-free perovskite solar cells. They used inkjet printing to deposit Methylammonium iodide (MAI) on top of a pre-deposited $\mathrm{PbI}_{2}$ layer, in a double step fashion. This approach led to well defined crystallinity in the Methylammonium lead tri-iodide $\left(\mathrm{MAPbI}_{3}\right)$ thin film, reaching high performance in solar cells of power conversion efficiency $(\mathrm{PCE})=11.60 \%$, open circuit voltage $\left(V_{\mathrm{oc}}\right)=0.95 \mathrm{~V}$, short circuit current density $\left(J_{\mathrm{sc}}\right)=17.20 \mathrm{~mA} \mathrm{~cm}^{-2}$, and fill factor $(\mathrm{FF})=71 \%$. Song and co-workers [8] investigated the influence of the printing table temperature of $\mathrm{MAI}$ and $\mathrm{PbI}_{2}$ on mesoporous $\mathrm{TiO}_{2}$, showing a strong correlation between printing table temperature and film morphology. A mild temperature $\left(50{ }^{\circ} \mathrm{C}\right)$ was found to result in larger crystals with high surface coverage, obtaining a maximum PCE of $7.9 \%$. By changing the perovskite composition and adding $\mathrm{MACl}$, the morphology and device performance were further improved, achieving PCE $\sim 12.3 \%, V_{\mathrm{oc}} \sim 0.91 \mathrm{~V}, J_{\mathrm{sc}} \sim 19.55 \mathrm{~mA} \mathrm{~cm}^{-2}$, and $\mathrm{FF} \sim 69 \%$. Hashmi et al. reported an all-printable and ambient-processed hole transport layer (HTL) -free mesoporous perovskite solar cell. The device architecture was glass/ Fluorine-doped Tin Oxide (FTO)/Titanium dioxide $\left(\mathrm{TiO}_{2}\right) /$ Zirconium dioxide $\left(\mathrm{ZrO}_{2}\right) / \mathrm{MAPbI}_{3} /$ carbon, and was fabricated by infiltrating the $\mathrm{MAPbI}_{3}$ precursors by piezo based inkjet printing in screen printed $\mathrm{TiO}_{2}, \mathrm{ZrO}_{2}$, and carbon layers [9]. They have used 5-ammonium valeric acid iodide (5-AVAI) in perovskite ink as a templating agent to improve the crystalline network and charge-carrier lifetime of $\mathrm{MAPbI}_{3}$. This additive also prevented the clogging of inkjet nozzles by slowing-down the perovskite crystal growth. Highly reproducible and stable devices were achieved with the highest PCE of 7.83\% under forward bias scan and $8.74 \%$ under reverse bias scan. Venkataraman et al. have tuned the composition of the perovskite layer for improving the performance and stability by in situ mixing of cations, Methylammonium (MA), and Formamidinium (FA) from separate ink cartridges using Red-Green-Blu (RGB) color codes of the multichannel inkjet printer [10]. They showed PCE of $11.1 \%, V_{\mathrm{oc}} \sim 0.87 \mathrm{~V}, J_{\mathrm{sc}} \sim 18.77 \mathrm{~mA} \mathrm{~cm}^{-2}, \mathrm{FF} \sim 68 \%$ in the $\mathrm{p}-\mathrm{i}-\mathrm{n}$ structure solar cell based on perovskite containing a MA:FA ratio of 2:1. Mathies et al. [11] introduced a vacuum-annealing step after the printed of precursor ink in one step, in order to replace the antisolvent quenching step used during spin-coating, which could not be adapted to ink-jet-printed perovskite. Three sublayers and a drop spacing of $45 \mu \mathrm{m}$ led to a PCE of $11.3 \%$. By following the same approach, Liang et al. [12] investigated the vacuum-assisted thermal annealing (VTA) post-treatment after the printing of perovskite, to accelerate the solvent evaporation and obtain a better morphology. Indeed, PCE of $17.04 \%$ was achieved for a small area device $\left(0.04 \mathrm{~cm}^{2}\right)$ and of $13.27 \%$ for a large area $\left(4 \mathrm{~cm}^{2}\right)$ in one-step printed deposition by using a mesoporous architecture.

The highest performance with mesoporous architecture was achieved by Li et al. [13] with a double step deposition. By exploring $\mathrm{PbI}_{2}$ ink precursor with various solvent compositions and using Methylammonium iodide vapor as a reaction agent to transform $\mathrm{PbI}_{2}$ to the $\mathrm{MAPbI}_{3}$, they reported a PCE of $18.63 \%$ for a small area device $\left(0.04 \mathrm{~cm}^{2}\right)$.

In this work, the printability of new inks based on perovskite and starch was investigated for the first time in view of a future development of a more scalable and cost-effective method. Very importantly, the composite perovskite:starch was proven to be more stable than the pristine perovskite. Herein, several starch-perovskite-based solutions, developed and previously deposited via spin coating [2], were investigated as inks for one-step ink-jet-printed deposition by optimizing all of the printing parameters. The best nanocomposite printed films were characterized by X-ray diffraction, UV visible absorption, morphological analyses (Optical microscope and Scanning electron microscopy), and photoluminescence measurements in view of future implementation in a full printed device. 


\section{Materials and Methods}

\subsection{Materials}

Lead (II) iodide $\mathrm{PbI}_{2}$ ultra-dry 99.999\% (metals basis) was purchased from Alfa Aesar (Haverhill, MA, USA), and Methylammonium iodide $\mathrm{CH}_{3} \mathrm{NH}_{3} \mathrm{I}$ (MAI) from GreatCell Solar (Queanbeyan, Australia). The corn starch used, Maizena, characterized by an A-type waxy corn structure [14], was supplied from Unilever (London, UK). Dimethyl sulfoxide anhydrous $99.9 \%$ (DMSO) and chlorobenzene anhydrous 99.8\% (CB) were purchased from Aldrich (Saint Louis, MO, USA). Poly [N,N0-bis(4-butylphenyl)-N,N0-bis(phenyl) benzidine] (poly-TPD) was from Solaris Chem Inc. (Saint-Lazare, QC, Canada). All the materials were used as received without any further purification.

\subsection{Methods}

\subsubsection{Poly-TPD Solution Preparation}

The solution of poly-TPD $(1.5 \mathrm{mg} / \mathrm{mL}$ in chlorobenzene $)$ was prepared by stirring at $40{ }^{\circ} \mathrm{C}$ for $2 \mathrm{~h}$.

\subsubsection{Starch-Perovskite Solution Preparation}

The perovskite precursor solution containing an equimolar precursor stoichiometry, i.e., MAI:PbI ${ }_{2}=1: 1$, was prepared by mixing $\mathrm{MAI}$ with $\mathrm{PbI}_{2}$ in $\mathrm{DMSO}$ with varying precursor weight concentrations in DMSO, i.e., 10-20-30 wt\%, as reported in Table 1 . The solutions were stirred on a hot plate at $80{ }^{\circ} \mathrm{C}$ for $30 \mathrm{~min}$. After precursor solubilization, different starch/precursor ratios were added to each solution, i.e., $1,5,10$, and $15 \mathrm{wt} \%$, and were stirred at $80{ }^{\circ} \mathrm{C}$ for $5 \mathrm{~h}$ in order to obtain a clear solution after starch solubilization. The identification name (ID) of each sample with the correspondent precursors and starch concentrations are reported in Table 1.

Table 1. Samples ID and compositions.

\begin{tabular}{|c|c|c|}
\hline Sample ID & $\mathrm{MAPbI}_{3} / \mathrm{DMSO}(\mathrm{wt} \%)$ & Starch/MAPbI ${ }_{3}(w t \%)$ \\
\hline $5 \mathrm{MAPbI}_{3}$ & 5 & 0 \\
\hline $5 \mathrm{MAPbI}_{3}-1 \mathrm{~S}$ & 5 & 1 \\
\hline $5 \mathrm{MAPbI}_{3}-5 \mathrm{~S}$ & 5 & 5 \\
\hline $5 \mathrm{MAPbI}_{3}-10 \mathrm{~S}$ & 5 & 10 \\
\hline $5 \mathrm{MAPbI}_{3}-15 \mathrm{~S}$ & 5 & 15 \\
\hline $10 \mathrm{MAPbI}_{3}$ & 10 & 0 \\
\hline $10 \mathrm{MAPbI}_{3}-1 \mathrm{~S}$ & 10 & 1 \\
\hline $10 \mathrm{MAPbI}_{3}-5 \mathrm{~S}$ & 10 & 5 \\
\hline $10 \mathrm{MAPbI}_{3}-10 \mathrm{~S}$ & 10 & 10 \\
\hline $10 \mathrm{MAPbI}_{3}-15 \mathrm{~S}$ & 10 & 15 \\
\hline $10 \mathrm{MAPbI}_{3}-20 \mathrm{~S}$ & 10 & 20 \\
\hline $20 \mathrm{MAPbI}_{3}$ & 20 & 0 \\
\hline $20 \mathrm{MAPbI}_{3}-1 \mathrm{~S}$ & 20 & 1 \\
\hline $20 \mathrm{MAPbI}_{3}-5 \mathrm{~S}$ & 20 & 5 \\
\hline $20 \mathrm{MAPbI}_{3}-10 \mathrm{~S}$ & 20 & 10 \\
\hline $20 \mathrm{MAPbI}_{3}-15 \mathrm{~S}$ & 20 & 15 \\
\hline $20 \mathrm{MAPbI}_{3}-20 \mathrm{~S}$ & 20 & 20 \\
\hline $30 \mathrm{MAPbI}_{3}$ & 30 & 0 \\
\hline $30 \mathrm{MAPbI}_{3}-1 \mathrm{~S}$ & 30 & 1 \\
\hline $30 \mathrm{MAPbI}_{3}-5 \mathrm{~S}$ & 30 & 5 \\
\hline $30 \mathrm{MAPbI}_{3}-10 \mathrm{~S}$ & 30 & 10 \\
\hline $30 \mathrm{MAPbI}_{3}-15 \mathrm{~S}$ & 30 & 15 \\
\hline
\end{tabular}




\subsubsection{Rheological Characterization of Perovskite Precursors Solutions}

The viscosity of the perovskite precursor solutions by varying the precursor concentrations in DMSO from 5 to $30 \mathrm{wt} \%$ and with a starch/precursor ratio from 1 to $15 \mathrm{wt} \%$, was carried out in a strain controlled rheometer (Malvern Kinexus Pro+, Malvern, UK) equipped by parallel plate geometry (radius $=12.5 \mathrm{~mm}$ ) in steady state mode with a shear rate ranging from $1-1000 \mathrm{~s}^{-1}$ at $23{ }^{\circ} \mathrm{C}$. All the liquid formulations were tested after stirring at $80{ }^{\circ} \mathrm{C}$ for $5 \mathrm{~h}$ and cooled to ambient temperature. This was in order to better understand the influence of precursor and starch concentrations on the viscosity of the as-prepared perovskite solutions before deposition. The rheological experiments were repeated three times to check the repeatability of the results.

\subsubsection{Surface Tension}

The surface tension of the inks was measured by Krüss DSA100 (Bristol, UK) using the pendant drop method.

\subsubsection{Inkjet Printing Process}

Patterns of $5 \mathrm{~mm} \times 5 \mathrm{~mm}$ with various print resolutions were designed using the open source software, GIMP (The General Image Manipulation Program, Spencer Kimball, Peter Mattis, 2.10 .8 version, Berkeley, CA, USA). The files were saved as bitmap (.bmp) image file format and opened with Dimatix drop manager (Fujifilm, Santa Clara, CA, USA) in order to be loaded by the printer software.

The printing frequency was set at $5.0 \mathrm{kHz}$ and a customized waveform was used. The voltage and the temperature of the cartridge were optimized based on the ink explored. The printing process was carried out in air with a humidity of 20-30\%. The temperature of the substrate was optimized during the process through print platform heating. The diameters of the printed drops were analyzed to optimize the drop spacing of each explored ink.

The substrate was prepared by washing the glass slide with isopropanol. Then, the poly-TPD solution $(1.5 \mathrm{mg} / \mathrm{mL}$ in clorobenzene) was printed at room temperature by using the same customized waveform with a drop spacing of $60 \mu \mathrm{m}$ (distance between droplets center to center) and a voltage of $23 \mathrm{~V}$. Printed poly-TPD was annealed in air at $140{ }^{\circ} \mathrm{C}$ for $30 \mathrm{~min}$, followed by UV treatment of $30 \mathrm{~min}$ in order to improve the wettability, as already demonstrated in our previous paper [2].

\subsubsection{Morphological Characterization}

The surface morphology of the single droplets printed and of the printed starch-perovskite composite samples was analyzed by an optical microscope (Nikon Eclipse-LV100ND, Tokyo, Japan). Scanning electron microscopy (SEM) images of the printed starch-perovskite composite samples, deposited on a glass/printed poly-TPD substrate, were collected by using Carl Zeiss Auriga 40 Crossbeam instrument (Oberkochen, Germany), in high vacuum and high-resolution acquisition mode, equipped with Gemini column and an integrated high efficiency in-lens detector. The applied acceleration voltage was $5 \mathrm{kV}$.

\subsubsection{XRD Measurements}

Wide-angle X-ray diffraction (XRD) patterns were obtained in reflection geometry by an automated Bruker D8 Advance diffractometer (Billerica, MA, USA), equipped with nickel-filtered Cu $\mathrm{K} \alpha$ radiation (1.5418 $\AA$ ) as the $\mathrm{X}$-ray source that was operated at $35 \mathrm{kV}$ and $40 \mathrm{~mA}$.

\subsubsection{UV-vis Absorption}

UV-visible optical absorption spectra were recorded on Varian Cary 500 spectrophotometer (Agilent, Santa Clara, CA, USA) in the $200-800 \mathrm{~nm}$ wavelength range at room temperature. 


\subsubsection{Photoluminescence (PL) Experiments}

Steady state and time resolved photoluminescence (PL) was measured by an Edinburgh FLS920 spectrometer (Livingstone, UK) equipped with a Peltier-cooled Hamamatsu R928 photomultiplier tube (185-850 nm). An Edinburgh Xe900 450 W Xenon arc lamp (Livingstone, UK) was used as exciting light source. Corrected spectra were obtained via a calibration curve supplied with the instrument (lamp power in the steady state PL experiments $\sim 0.6 \mathrm{~mW} \mathrm{~cm}^{-2}$, spot area $0.5 \mathrm{~cm}^{2}$ ). Emission lifetimes were determined with the single photon counting technique by means of the same Edinburgh FLS980 spectrometer (Livingstone, UK), using a laser diode as excitation source $\left(1 \mathrm{MHz}, \lambda_{\mathrm{exc}}=635 \mathrm{~nm}, 67 \mathrm{ps}\right.$ pulse width, and about 30 ps time resolution after deconvolution) and a Hamamatsu MCP R3809U-50 (time resolution $20 \mathrm{ps}$ ) as detector (laser power in the time resolution photoluminescence (TRPL) experiment $\sim 1.6 \mathrm{~W} \mathrm{~cm}^{-2}$, spot area $0.3 \mathrm{~mm}^{2}$ ) [15].

\section{Results and Discussion}

The printability of the starch-perovskite-based inks [2] was explored with the aim to evaluate the possibility to deposit them through large scale methods. The printability of a solution can be defined by the $\mathrm{Z}$ parameter that is directly dependent on viscosity, surface tension, and density of the ink [16-18]. Therefore, these properties were, firstly, evaluated in order to select the solutions more suitable for ink jet printing technology.

Figure 1 showed the steady state viscosity of the different solutions investigated, including a wide range of perovskite precursor concentrations from 5 to $30 \mathrm{wt} \%$ and starch/precursor concentrations from 0 to $15 \mathrm{wt} \%$. All the perovskite precursor formulations, without starch, showed a Newtonian behavior with almost constant viscosity ranges from $\sim 0.002$ to $\sim 0.007 \mathrm{~Pa}$ s by increasing the precursors content. By increasing the starch content, at lower perovskite precursor concentrations, i.e., 5 and $10 \mathrm{wt} \%$, the solutions still showed a Newtonian behavior, with an increased viscosity up to $\sim 0.01 \mathrm{~Pa}$. By increasing the perovskite precursors ratio to 20 and $30 \mathrm{wt} \%$, a pseudoplastic behavior was observed in the presence of starch content higher than $5 \mathrm{wt} \%$.
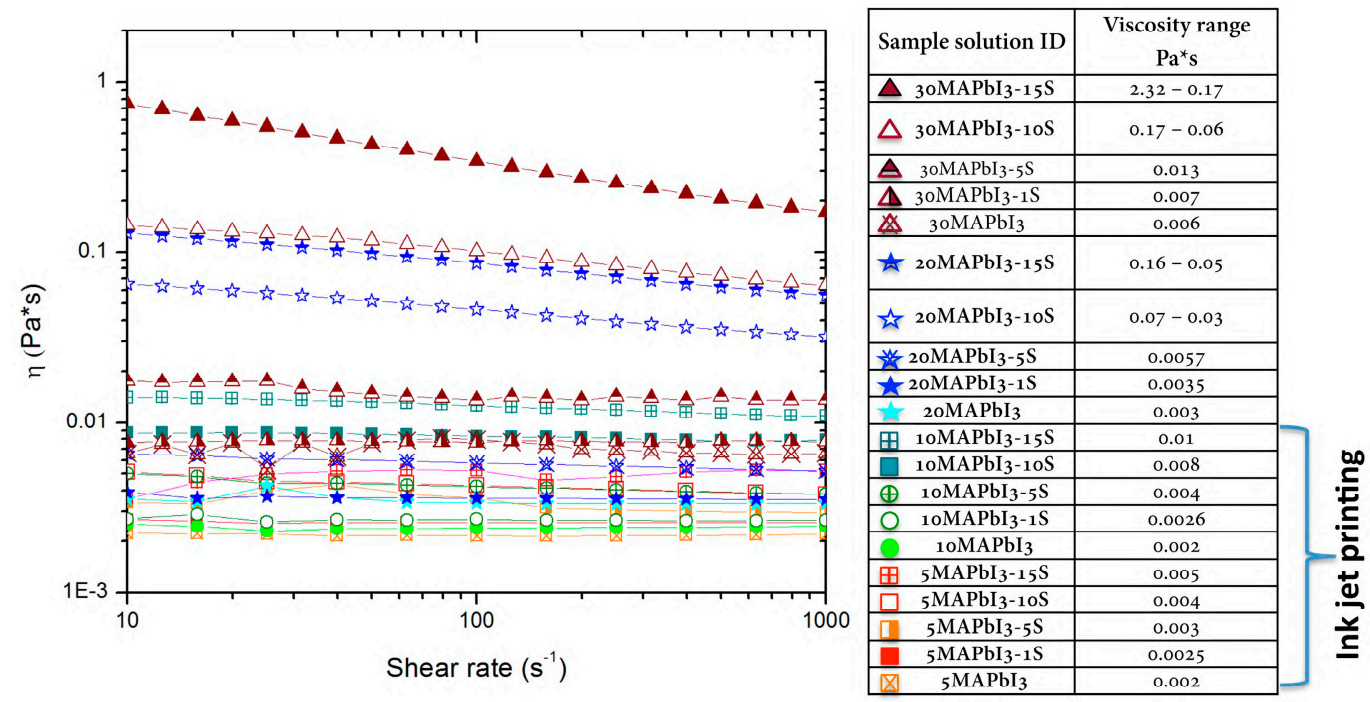

Figure 1. Rheological characterization of the perovskite-starch-based solutions investigated by varying the precursors and starch concentrations.

The starch used for the solutions was widely characterized in our previous work [14], as well as its role as a rheological modifier [2], with the interesting discovery that the gelatinization process of the starch into DMSO together with the interaction between the $\mathrm{OH}$ groups of the starch and the perovskite precursors highly influences the rheological behavior of the solutions. Interestingly, the results of the rheological characterization showed that by tuning the concentration of the precursors and of 
the starch, it is possible to obtain a solution with rheological properties suitable to the deposition technology used. By decreasing the perovskite precursor ratio down to $5-10 \mathrm{wt} \%$, we were able to move from spin coating to ink jet printing of perovskite-starch deposition. Together with the viscosity, the surface tension and the density of the inks are key parameters to investigate the "ejectability" of a solution. In general, values between $20-40 \mathrm{mN} / \mathrm{m}$ are considered more suitable for ink jet printing processes, lower than the surface tension values reported in Table 2 for the solutions with varying perovskite precursors, from 5 to $10 \mathrm{wt} \%$, and starch content from 0 to $10 \mathrm{wt} \%$. The respective densities, calculated by weighing a known volume of each solution, were reported in Table 2, together with the Z value calculated by Equation (1).

$$
Z=(\rho a \gamma)^{1 / 2} / \eta
$$

where $\eta$ is the dynamic viscosity, $\rho$ is the density, $\gamma$ is the surface tension, $a$ is the characteristic length (usually the nozzle diameter) of the ink.

Table 2. Density, surface tension, viscosity, and $Z$ parameter of the inks explored.

\begin{tabular}{ccccc}
\hline Ink & Density $(\mathbf{g} / \mathbf{m L})$ & Surface Tension $(\mathbf{m N} / \mathbf{m})$ & Viscosity at $23{ }^{\circ} \mathbf{C}(\mathbf{m P a} \mathbf{s})$ & $Z$ \\
\hline $5 \mathrm{MAPbI}_{3}$ & 1.095 & $44.24 \pm 0.15$ & 2 & 15.94 \\
\hline $5 \mathrm{MAPbI}_{3}-5 \mathrm{~S}$ & 1.369 & $53.34 \pm 0.15$ & 3 & 13.05 \\
\hline $5 \mathrm{MAPbI}_{3}-10 \mathrm{~S}$ & 1.365 & $53.15 \pm 0.27$ & 4 & 9.75 \\
\hline $10 \mathrm{MAPbI}_{3}$ & 1.375 & $53.39 \pm 0.32$ & 2 & 19.63 \\
\hline $10 \mathrm{MAPb}_{3}-5 \mathrm{~S}$ & 1.392 & $53.32 \pm 0.16$ & 4 & 9.86 \\
\hline $10 \mathrm{MAPbI}_{3}-10 \mathrm{~S}$ & 1.410 & $53.30 \pm 0.33$ & 8 & 4.96 \\
\hline
\end{tabular}

The solution containing the $5 \mathrm{wt} \%$ of perovskite precursor in solvent showed a surface tension of $44.24 \pm 0.15 \mathrm{mN} / \mathrm{m}$, close to the solvent used for the solution, DMSO $(45.25 \pm 0.47 \mathrm{mN} / \mathrm{m})$. In the presence of starch, as well as with a higher precursor concentration, the surface tension increases up to about $53 \mathrm{mN} / \mathrm{m}$. As reported in Table $2, \mathrm{Z}$ values decreased by increasing the starch content, driven by the increased viscosity, and were much lower for the ink containing $10 \mathrm{wt} \%$ of precursors, showing a good influence of the presence of the starch on the ink ejectability calculated from $Z$. Indeed, $Z$ values between 1 and 10 are more suitable for ink jet printing technology, even though the value of a printable $\mathrm{Z}$ number is still under investigation [19-21].

Subsequently, the ejectability of the inks was experimentally investigated by applying several customized waveforms to the nozzle of the cartridge and by optimizing the voltage and the temperature applied to obtain a drop ejected from the nozzle, as shown in Figure 2.

After optimization of the previous parameters, interesting results were obtained for most of the inks reported in Table 1, by setting the voltage of the piezoelectric driven print-heads at each nozzle at $23 \mathrm{~V}$ and the temperature of the print-head at $23^{\circ} \mathrm{C}$. On the other hand, for the formulations containing higher starch concentration, $5 \mathrm{MAPbI}_{3}-10 \mathrm{~S}, 10 \mathrm{MAPbI}_{3}-5 \mathrm{~S}$, and $10 \mathrm{MAPbI}_{3}-10 \mathrm{~S}$, higher voltage and temperature were necessary to allow the ejection of the ink from the nozzle, i.e., $30 \mathrm{~V}$ and $40{ }^{\circ} \mathrm{C}$, and $40 \mathrm{~V}$ and $45^{\circ} \mathrm{C}$, respectively. This latter result was probably due to the combination of higher surface tension and viscosity, despite the lower $Z$ parameter calculated. It is interesting to observe that the shape and the length of the drop were highly influenced by the concentration of starch. In detail, increasing starch molecular concentration lead to a longer drop tail due to greater long chain content, typical of polymers with high molecular weight-based solutions [22]. 


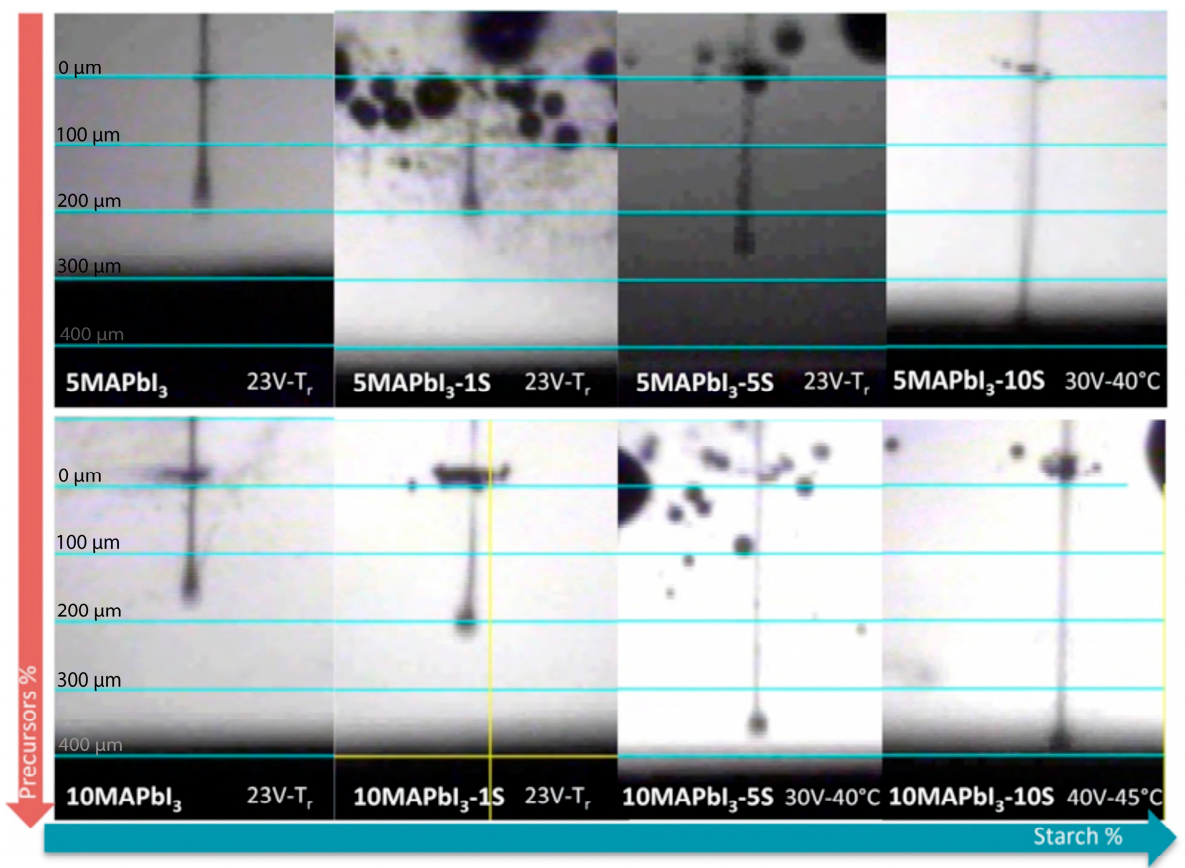

Figure 2. Droplets ejected from the nozzle for the different inks explored.

Figure 3 shows single droplets of the perovskite inks deposited on printed and annealed poly-TPD by varying perovskite precursors and starch concentrations, before thermal treatment. It is evident that the size of the drops increases from about $48.9 \pm 4.9 \mu \mathrm{m}$ for $5 \mathrm{wt} \%$ and $52.8 \pm 1.3 \mu \mathrm{m}$ for $10 \mathrm{wt} \%$, in absence of starch, up to $61.2 \pm 0.4 \mu \mathrm{m}$ and $66.2 \pm 1.3 \mu \mathrm{m}$, respectively, after adding $10 \mathrm{wt} \%$ of the biopolymer. Moreover, the presence of the starch allows for a more compact and homogeneous drop on the substrate to be obtained, which is a key aspect in order to realize a good photoactive film.

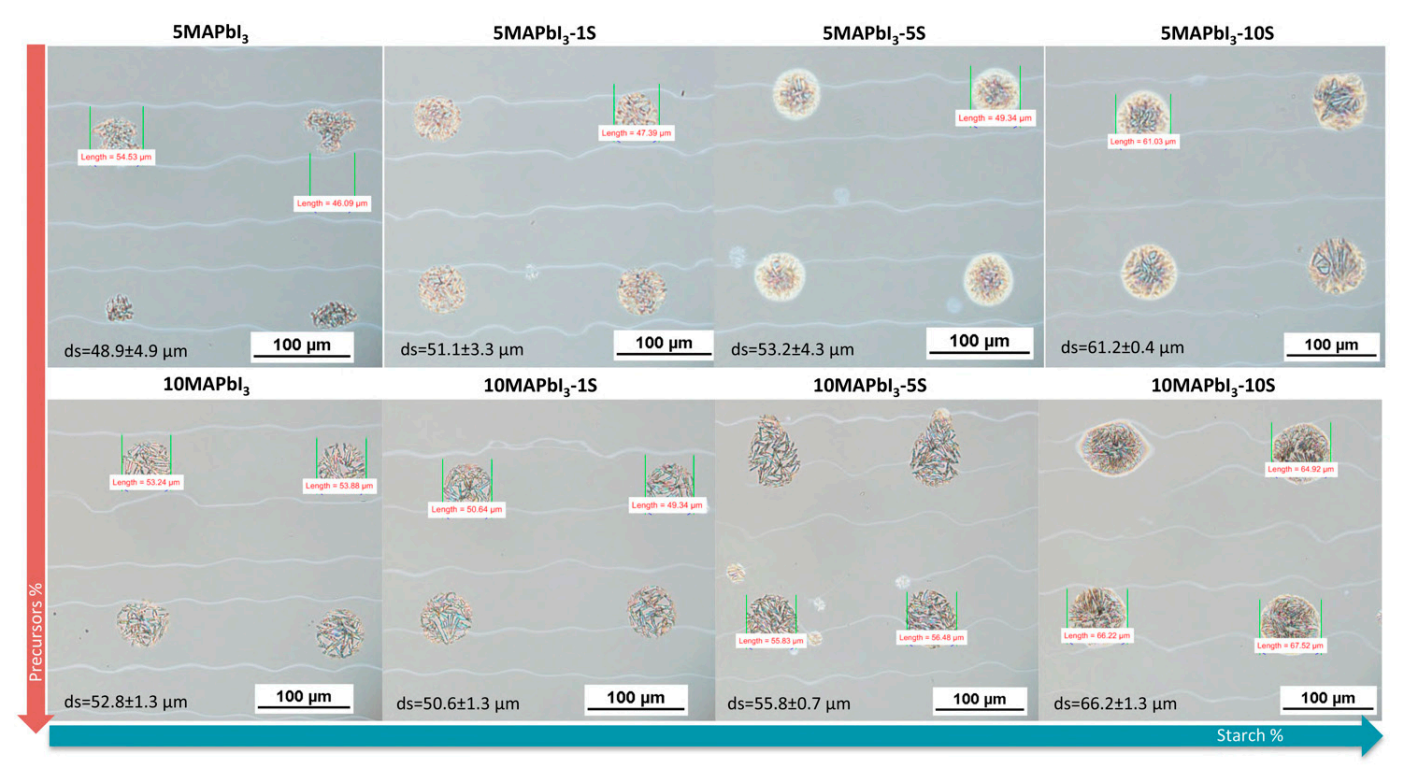

Figure 3. Single droplets of the inks deposited on printed and annealed poly-TPD by varying perovskite precursors and starch concentrations.

From droplet to pattern printing, there are several aspects to consider; first, the choice of a proper drop space, in order to have the appropriate overlapping of the droplets, which is essential to obtain a continuous pattern. Hence, drop size is a crucial parameter and depends on the ink, wettability of the substrate, and surface temperature as well. As the diameter of the print head nozzle is fixed, 
the droplet overlap is controlled by increasing or decreasing the resolution of the image (dpi) of the pattern [23].

By considering the average drop size of the different inks tested, a drop space of $30 \mu \mathrm{m}$ was firstly selected to be used for printing continuous patterns. In addition, several annealing temperatures, from 80 to $110{ }^{\circ} \mathrm{C}$, were explored for printed perovskite precursor films and shown in Figure 4a.

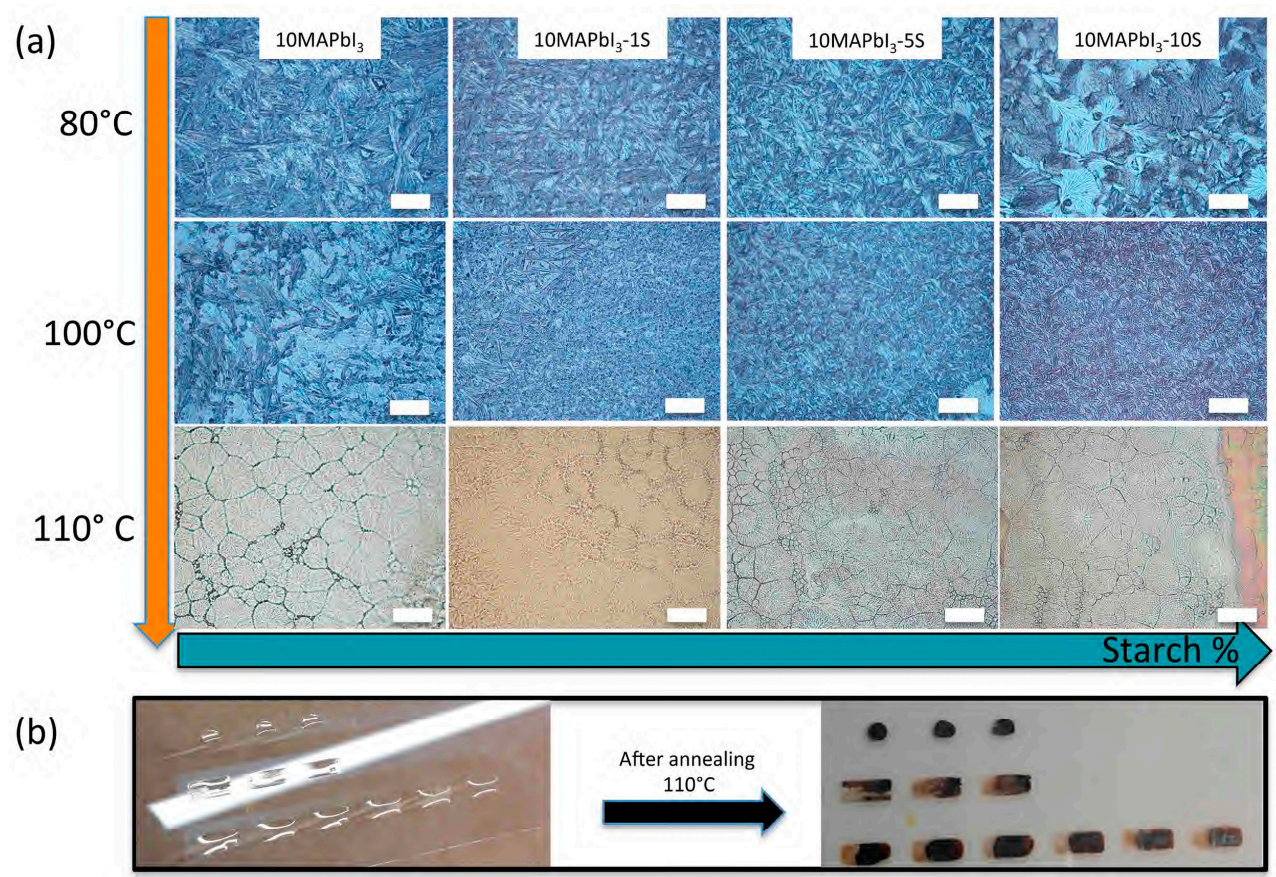

Figure 4. Optical microscope images of different precursor perovskite solution printed patterns annealed at different temperatures (scale bar $100 \mu \mathrm{m})(\mathbf{a})$, and "shift" of the drops observed after thermal annealing at $110^{\circ} \mathrm{C}$ for different starch concentrations (b).

All of the films annealed at 80 and $100{ }^{\circ} \mathrm{C}$ resulted in a needle-like morphology organized in smaller islands, by increasing the temperature and the starch content (at fixed temperature). After annealing at $110^{\circ} \mathrm{C}$, a more compact morphology was observed, irrespective of the starch content, suggesting that the rate of the solvent evaporation is a key point during perovskite film formation; by increasing the annealing temperature, then the rate of DMSO evaporation, a better perovskite grain morphology could be obtained. However, a "shift" of the drops was observed during thermal annealing, leading to a non-homogeneous perovskite film, as shown in the pictures in Figure $4 \mathrm{~b}$, which was more evident as the starch content decreased.

Furthermore, with the aim to overcome the crystallization issue by increasing the solvent evaporation rate, and to better control the uniformity of the printed pattern, the perovskite precursor-based inks containing 5 and $10 \mathrm{wt} \%$ of precursors and $5 \mathrm{wt} \%$ of starch were printed on a hot substrate at 90 and $100{ }^{\circ} \mathrm{C}$. As shown in the optical images reported in Figure 5, for both of the concentrations explored, a higher temperature of the substrate enabled a morphology characterized by perovskite grains, whereas a needles-like structure was observed by depositing the $5 \mathrm{wt} \%$ of starch perovskite at $90{ }^{\circ} \mathrm{C}$. Therefore, $100{ }^{\circ} \mathrm{C}$ was selected as the best printing temperature. Moreover, a well-defined $5 \times 5 \mathrm{~mm}^{2}$ printed pattern was obtained, as shown in the inset of Figure 5 . 


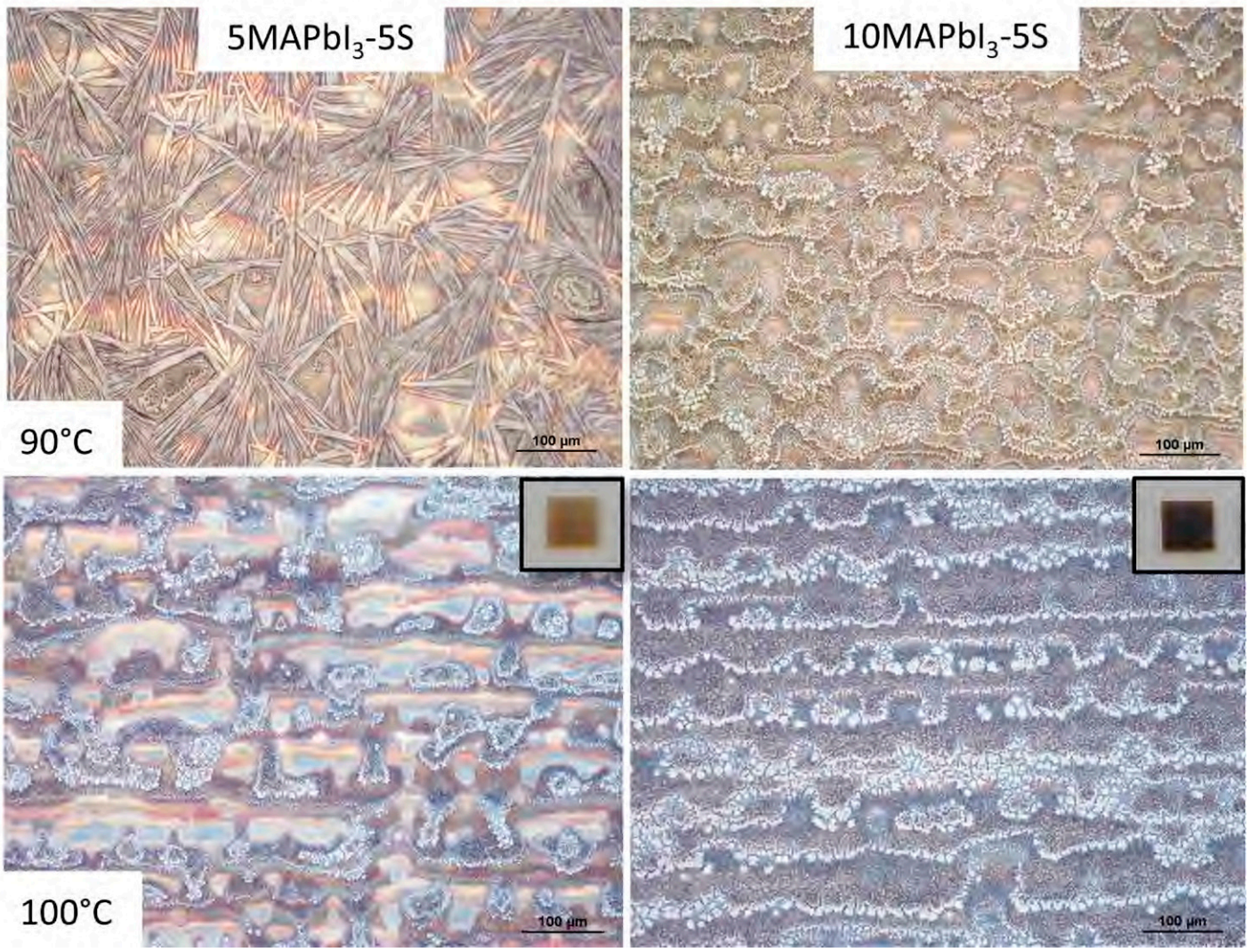

Figure 5. Optical images of $5 \mathrm{MAPbI}_{3}-5 \mathrm{~S}$ and $10 \mathrm{MAPbI}_{3}-5 \mathrm{~S}$ samples printed at $90^{\circ}$ and $100{ }^{\circ} \mathrm{C}$, and photo of the $5 \times 5 \mathrm{~mm}^{2}$ printed pattern in the inset.

With the aim to improve the coverage of the substrate, the drop space was decreased from 30 to $15 \mu \mathrm{m}$, leading to a more compact and homogeneous film, as shown in Figure 6 for $10 \mathrm{MAPbI}_{3}-5 \mathrm{~S}$ perovskite ink.

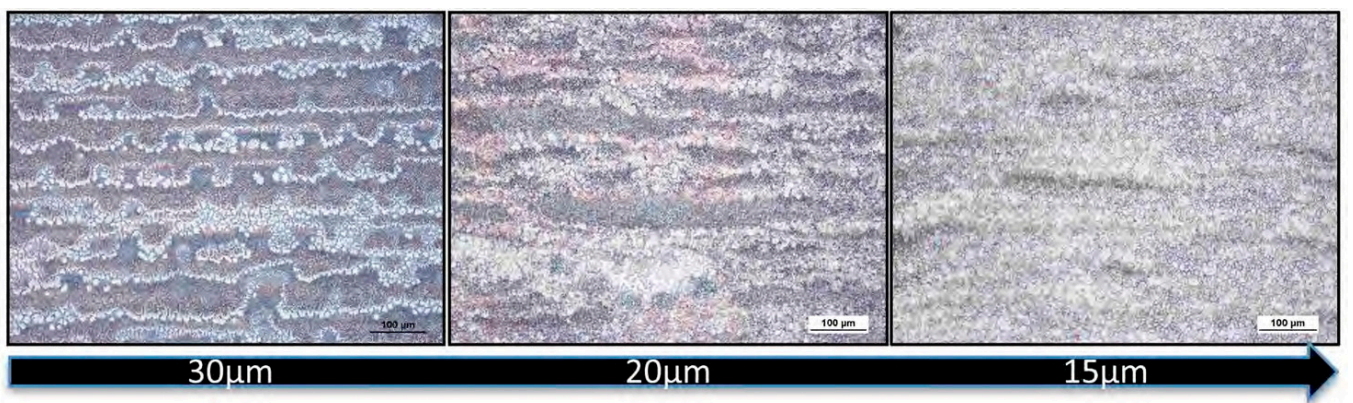

Figure 6. The $10 \mathrm{MAPbI}_{3}-5 \mathrm{~S}$ samples printed at $100{ }^{\circ} \mathrm{C}$ by using a drop spacing of 30,20 , and $15 \mu \mathrm{m}$.

Therefore, in the following experiment, $5 \mathrm{MAPbI}_{3}-5 \mathrm{~S}$ and $10 \mathrm{MAPbI}_{3}-5 \mathrm{~S}$ were printed according to the optimized parameters and the respective films were accurately characterized and compared.

The SEM images in Figure 7a,b show a morphology characterized by large grains of about $5 \mu \mathrm{m}$ in both samples. However, slightly larger and more compact grains were observed for $10 \mathrm{MAPbI}_{3}-5 \mathrm{~S}$, combined with a smaller quantity of gaps than $5 \mathrm{Mapi}-5 \mathrm{~S}$ film. The X-ray diffraction patterns on $5 \mathrm{MAPbI}_{3}-5 \mathrm{~S}$ and $10 \mathrm{MAPbI}_{3}-5 \mathrm{~S}$ printed film in Figure $7 \mathrm{c}$ display a strong peak at $14.2^{\circ}$ of the $\mathrm{MAPbI}_{3}$ crystal. However, the presence of a small peak at $12.7^{\circ}$, in both of the samples, suggested the presence of unreacted $\mathrm{PbI}_{2}$ in the film, maybe due to the deposition conditions (in air, in presence of humidity). The characteristic absorption spectra of perovskite were shown for both of the concentrations explored 
in Figure 7d, with higher absorption intensity by increasing the precursor concentration due to the increasing thickness of the film from about $1 \mu \mathrm{m}\left(5 \mathrm{MAPbI}_{3}-5 \mathrm{~S}\right)$ to $1.7 \mu \mathrm{m}\left(10 \mathrm{MAPbI}_{3}-5 \mathrm{~S}\right)$. It is interesting to observe that thicker and more opaque films were achieved by inkjet depositing perovskite inks at low precursor concentrations of 5 and $10 \mathrm{wt} \%$, when compared to conventional spin-coating [2]. Moreover, despite the high thickness, printed perovskite films are highly converted, as demonstrated by XRD patterns, which did not evidence the presence of peaks related to MAI-DMSO-PbI 2 intermediate complex $\left(6.6^{\circ}, 7.2^{\circ}\right.$, and $\left.9.2^{\circ}\right)[24]$.
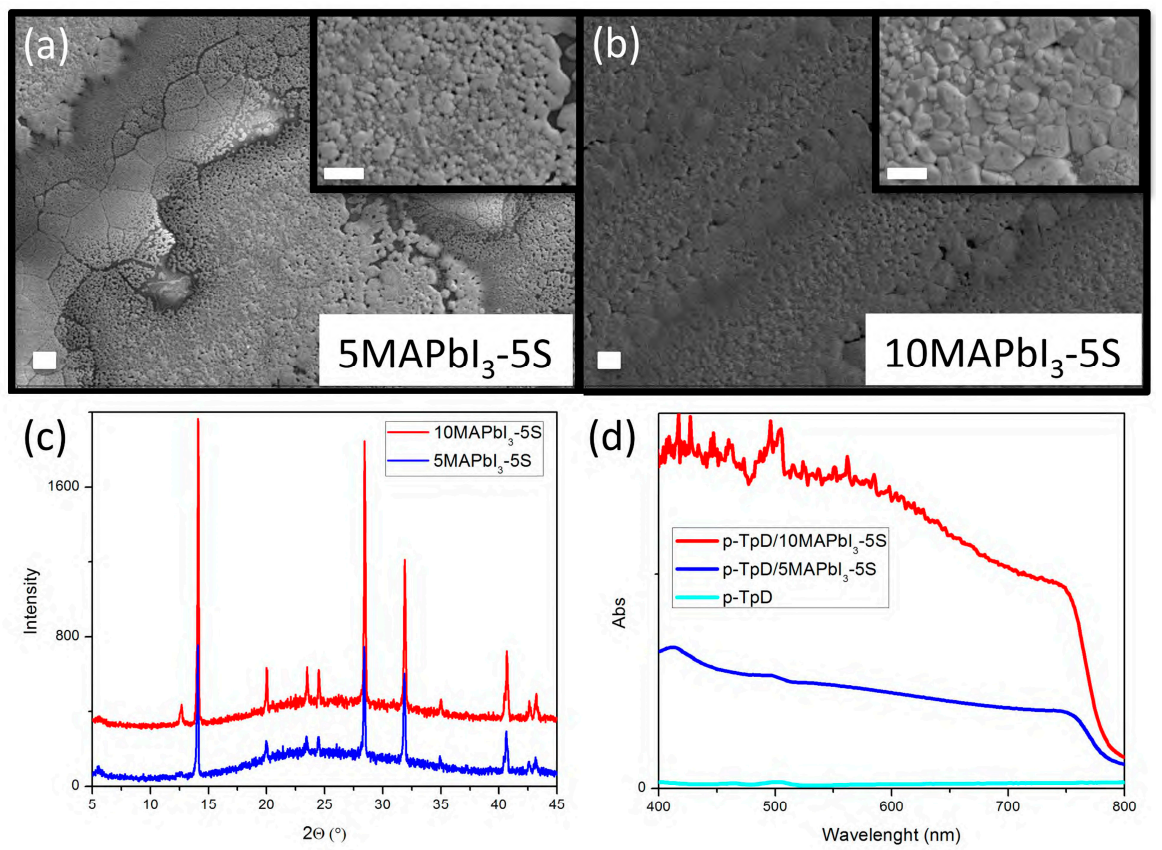

Figure 7. Scanning electron microscopy (SEM) images (a,b), X-ray diffraction (XRD) spectra (c), and UV-visible absorption (d) of $5 \mathrm{MAPbI}_{3}-5 \mathrm{~S}$ and $10 \mathrm{MAPbI}_{3}-5 \mathrm{~S}$ printed pattern film on glass/printed poly-TPD substrate. Scale bars $10 \mu \mathrm{m}$.

Aiming at future optoelectronic applications, the optical properties of the printed films were investigated by steady-state PL measurements, as shown in Figure 8. The intense PL emission band of $10 \mathrm{MAPbI}_{3}-5 \mathrm{~S}$ peaks at $795 \mathrm{~nm}$, and it is slightly blue, shifting to $790 \mathrm{~nm}$ for $5 \mathrm{MAPbI}_{3}-5 \mathrm{~S}$. The emission band position and intensities are in line with what was previously reported for these composites, and suggests good optoelectronic properties for the perovskite component of the ink [25].
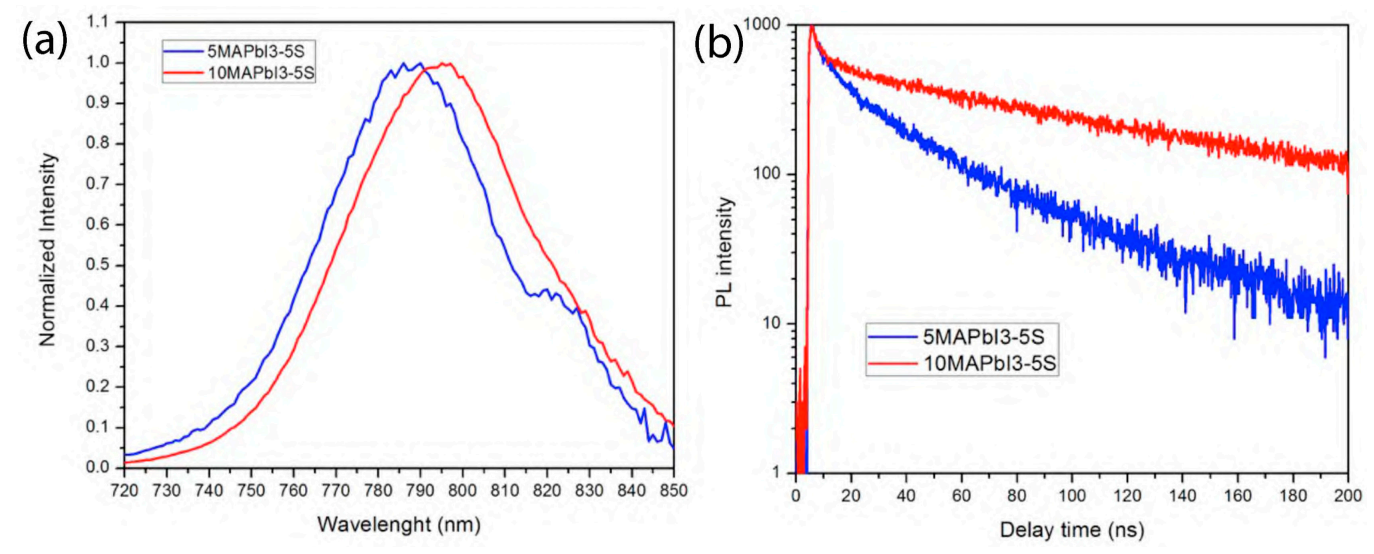

Figure 8. Photoluminescence (PL) spectra (a) and PL lifetime decay (b) of $5 \mathrm{MAPbI}_{3}-5 \mathrm{~S}$ and $10 \mathrm{MAPbI}_{3}-5 \mathrm{~S}$ printed pattern film. 
The time-resolved PL experiment (Figure 8b) further supports the claim of good optoelectronic properties, as the lifetimes are reasonably long (9, 52 ns for $5 \mathrm{MAPbI}_{3}-5 \mathrm{~S}$; and 5, $124 \mathrm{~ns}$ for $\left.10 \mathrm{MAPbI}_{3}-5 \mathrm{~S}\right)$ and suggest reduced parasite traps mediated the carrier's recombination. The role of the starch has already been proven to positively affect the optoelectronic properties of perovskite materials. Herein, the increase of the lifetime associated to a higher precursor concentration suggests better optoelectronic properties for $10 \mathrm{MAPbI}_{3}-5 \mathrm{~S}$ film, which could be due to an increase of the perovksite grain dimensions.

\section{Conclusions}

In this work, the possibility to print the starch-perovskite inks, developed in our previous work, was explored by using ink jet printing as a first step towards a more scalable deposition process of perovskite-based devices. The tunability of the viscosity of the starch-perovskite-based inks allowed us to select the suitable concentration to be used as printable inks. Through the investigation of the printing parameters, such as waveform, voltage, and temperature of piezoelectric driven print heads from one side, and drop space, substrate temperature from the other, printed perovskite films with good morphological, crystalline, and optical properties were realized. These results represent the first demonstration of the versatility of the perovskite deposition approach developed during this work, and open the possibility for further investigations towards upscaling of perovskite deposition.

Author Contributions: Conceptualization, A.G., C.E.C., E.S., A.R.; methodology, E.S., C.T., C.E.C.; software, E.S.; validation, A.G., E.S.; formal analysis, E.S.; investigation, A.G., A.L., E.S., resources, C.T.; data curation, A.G., E.S; writing—original draft preparation, A.G.; writing-review and editing, A.G., A.R., C.T., C.E.C., S.C.; visualization, C.E.C., C.T., A.R; supervision, C.E.C., C.T., A.R.; project administration, C.E.C., C.T., A.R.; funding acquisition, C.T.

Funding: This research was funded by Engineering Physical Science Research Council (EPSRC) Grant Ref: $\mathrm{EP} / \mathrm{I} 033335 / 2$.

Acknowledgments: The authors acknowledge Mr. Donato Cannoletta for technical support.

Conflicts of Interest: The authors declare no conflict of interest.

\section{References}

1. Peng, X.; Yuan, J.; Shen, S.; Gao, M.; Chesman, A.S.R.; Yin, H.; Cheng, J.; Zhang, Q.; Angmo, D. Perovskite and organic solar cells fabricated by inkjet printing: progress and prospects. Adv. Funct. Mater. 2017, 27, 1703704. [CrossRef]

2. Giuri, A.; Masi, S.; Listorti, A.; Gigli, G.; Colella, S.; Corcione, C.E.; Rizzo, A. Polymeric rheology modifier allows single-step coating of perovskite ink for highly efficient and stable solar cells. Nano Energy 2018, 54, 400-408. [CrossRef]

3. Ding, B.; Li, Y.; Huang, S.-Y.; Chu, Q.-Q.; Li, C.-X.; Li, C.-J.; Yang, G.-J. Material nucleation/growth competition tuning towards highly reproducible planar perovskite solar cells with efficiency exceeding $20 \%$. J. Mater. Chem. A 2017, 5, 6840-6848. [CrossRef]

4. Wang, Z.-K.; Gong, X.; Li, M.; Hu, Y.; Wang, J.-M.; Ma, H.; Liao, L.S. Induced crystallization of perovskites by a perylene underlayer for high-performance solar cells. ACS Nano 2016, 10, 5479-5489. [CrossRef]

5. Van Franeker, J.J.; Voorthuijzen, W.; Gorter, H.; Hendriks, K.H.; Janssen, R.A.; Hadipour, A.; Andriessen, R.; Galagan, Y. All-solution-processed organic solar cells with conventional architecture. Sol. Mater. Sol. Cells 2013, 117, 267-272. [CrossRef]

6. Singh, M.; Haverinen, H.M.; Dhagat, P.; Jabbour, G.E. Inkjet printing_Process and its applications. Adv. Mater. 2010, 22, 673-685. [CrossRef] [PubMed]

7. Wei, Z.; Chen, H.; Yan, K.; Yang, S. Inkjet printing and instant chemical transformation of a $\mathrm{CH}_{3} \mathrm{NH}_{3} \mathrm{PbI}_{3} /$ nanocarbon electrode and interface for planar perovskite solar cells. Angew. Chem. Int. Ed. 2014, 53, 13239-13243. [CrossRef] [PubMed]

8. Li, S.-G.; Jiang, K.-J.; Su, M.-J.; Cui, X.-P.; Huang, J.-H.; Zhang, Q.-Q.; Zhou, X.-Q.; Yang, L.-M.; Song, Y.-L. Inkjet printing of $\mathrm{CH}_{3} \mathrm{NH}_{3} \mathrm{PbI}_{3}$ on a mesoscopic $\mathrm{TiO}_{2}$ film for highly efficient perovskite solar cells. J. Mater. Chem. A 2015, 3, 9092-9097. [CrossRef] 
9. Hashmi, S.G.; Martineau, D.; Li, X.; Ozkan, M.; Tiihonen, A.; Dar, M.I.; Sarikka, T.; Zakeeruddin, S.M.; Paltakari, J.; Lund, P.D.; et al. Air processed inkjet infiltrated carbon based printed perovskite solar cells with high stability and reproducibility. Adv. Mater. Technol. 2017, 2, 1600183. [CrossRef]

10. Bag, M.; Jiang, Z.; Renna, L.A.; Jeong, S.P.; Rotello, V.M.; Venkataraman, D. Rapid combinatorial screening of inkjet-printed alkyl-ammonium cations in perovskite solar cells. Mater. Lett. 2016, 164, 472-475. [CrossRef]

11. Mathies, F.; Abzieher, T.; Hochstuhl, A.; Glaser, K.; Colsmann, A.; Paetzold, U.W.; Hernandez-Sosa, G.; Lemmer, U.; Quintilla, A. Multipass inkjet printed planar methylammonium lead iodide perovskite solar cells. J. Mater. Chem. A 2016, 4, 19207-19213. [CrossRef]

12. Liang, C.; Li, P.; Gu, H.; Zhang, Y.; Li, F.; Song, Y.; Shao, G.; Mathews, N.; Xing, G. One-Step Inkjet Printed Perovskite in Air for Efficient Light Harvesting. Sol. RRL. 2018, 2, 1700217. [CrossRef]

13. Li, P.; Liang, C.; Bao, B.; Li, Y.; Hu, X.; Wang, Y.; Zhang, Y.; Li, F.; Shao, G.; Song, Y. Inkjet manipulated homogeneous large size perovskite grains for efficient and large-area perovskite solar cells. Nano Energy 2018, 46, 203-211. [CrossRef]

14. Giuri, A.; Colella, S.; Listorti, A.; Rizzo, A.; Corcione, C.E. Biodegradable extruded thermoplastic maize starch for outdoor applications. J. Therm. Anal. 2018, 134, 549-558. [CrossRef]

15. Masi, S.; Aiello, F.; Listorti, A.; Balzano, F.; Altamura, D.; Giannini, C.; Caliandro, R.; Uccello-Barretta, G.; Rizzo, A.; Colella, S. Connecting the solution chemistry of $\mathrm{PbI}_{2}$ and MAI: A cyclodextrin-based supramolecular approach to the formation of hybrid halide perovskites. Chem. Sci. 2018, 9, 3200-3208. [CrossRef]

16. Zhang, F.; Tuck, C.; Hague, R.; He, Y.; Saleh, E.; Li, Y.; Sturgess, C.; Wildman, R. Inkjet printing of polyimide insulators for the 3D printing of dielectric materials for microelectronic applications. J. Appl. Polym. Sci. 2016, 133. [CrossRef]

17. Gheno, A.; Huang, Y.; Bouclé, J.; Ratier, B.; Rolland, A.; Even, J.; Vedraine, S. Toward Highly Efficient Inkjet-Printed Perovskite Solar Cells Fully Processed Under Ambient Conditions and at Low Temperature. Sol. RRL 2018, 2, 1800191. [CrossRef]

18. Zhumekenov, A.A.; Burlakov, V.M.; Saidaminov, M.I.; Alofi, A.; Haque, M.A.; Turedi, B.; Davaasuren, B.; Dursun, I.; Cho, N.; El-Zohry, A.M.; et al. The Role of Surface Tension in the Crystallization of Metal Halide Perovskites. ACS Lett. 2017, 2, 1782-1788. [CrossRef]

19. Tai, J.; Gan, H.Y.; Liang, Y.N.; Lok, B.K. Control of Droplet Formation in Inkjet Printing Using Ohnesorge Number Category: Materials and Processes. Presented at the 2008 10th Electronics Packaging Technology Conference (EPTC 2008), Singapore, Singapore, 9-12 December 2008; pp. 761-766.

20. Jang, D.; Kim, D.; Moon, J. Influence of Fluid Physical Properties on Ink-Jet Printability. Langmuir 2009, 25, 2629-2635. [CrossRef]

21. Saleh, E.; Woolliams, P.; Clarke, B.; Gregory, A.; Greedy, S.; Smartt, C.; Wildman, R.; Ashcroft, I.; Hague, R.; Dickens, P.; et al. 3D inkjet-printed UV-curable inks for multi-functional electromagnetic applications. Addit. Manuf. 2017, 13, 143-148. [CrossRef]

22. De Gans, B.; Duineveld, P.C.; Schubert, U.S. Inkjet printing of polymers: State of the art and future developments. Adv. Mater. 2004, 16, 203-213. [CrossRef]

23. Vaithilingam, J.; Simonelli, M.; Saleh, E.; Senin, N.; Wildman, R.D.; Leach, R.K.; Tuck, C.J.; Hague, R.J. Combined Inkjet Printing and Infra-red Sintering of Silver Nanoparticles using a Swathe-by-swathe and Layer-by-layer approach for 3-dimensional Structures. ACS Appl. Mater. Interfaces 2017, 9, 6560-6570. [CrossRef]

24. Jeon, N.J.; Noh, J.H.; Kim, Y.C.; Yang, W.S.; Ryu, S.; Seok, S.I. Solvent engineering for high-performance inorganic-organic hybrid perovskite solar cells. Nat. Mater. 2014, 13, 897-903. [CrossRef]

25. Giuri, A.; Yuan, Z.; Miao, Y.; Wang, J.; Gao, F.; Sestu, N.; Saba, M.; Bongiovanni, G.; Colella, S.; Corcione, C.E.; et al. Ultra-Bright Near-Infrared Perovskite Light-Emitting Diodes with Reduced Efficiency Roll-off. Sci. Rep. 2018, 8, 15496. [CrossRef]

(C) 2019 by the authors. Licensee MDPI, Basel, Switzerland. This article is an open access article distributed under the terms and conditions of the Creative Commons Attribution (CC BY) license (http:/ / creativecommons.org/licenses/by/4.0/). 